\title{
Innovative Algorithm of Vector Translation Method for the Measurements of Corners of Building Structures Using RTN GNSS Technology**
}

\section{Introduction}

A building structure is one of the most difficult field details to be measured. This situation is even more complicated when we use RTN GNSS technology for the measurements. The Regulation [4], in addition to the measurement methods specified in the content of $\S 8$ and $\S 9$, also allows to use other solutions that meet the relevant accuracy requirements. The commonly used classical indirect method of line-line intersection, as an element supporting the real-time measurement technology, however, leaves much doubt as to the quality of the final results. Therefore, some modifications should be introduced in the entire calculation process, the result of which would be the final position of a building structure. In [2, 3], the author has already presented some calculation improvements to increase the reliability of the yielded coordinates of the corners of building structures, performed in the RTN GNSS mode. This article is the result of a consolidation of the author's existing research achievements, together with some additional proposals, and it illustrates the use of an innovative calculation algorithm called the method of vector translation.

Due to the limited volume of the article, only a general outline of the algorithm has been presented. The key assumption of this innovative solution in modeling the coordinates of the corners of building structures is to use the half-angle method [3], as well as the lengths of the vectors created between the points calculated from the classical method of line-line intersection and the corners of building structures obtained by the half-angle method. Additionally, in the process of increasing the reliability of determining the coordinates of the corners of building structures, the assumption of the right angles at the extreme apexes and the method of vector addition [2] are twice taken into account. For some points (corners of buildings),

* AGH University of Science and Technology, Faculty of Mining Surveying and Environmental Engineering, Department of Geomatics, Krakow, Poland

** This work was carried out within the statutory studies of the AGH University of Science and Technology, Faculty of Mining Surveying and Environmental Engineering No. 11.11.150.006 
additional determination of the position, resulting from the intersection of straight lines of the wall faces already modified, is also applied. The aim of the conducted study was to empirically demonstrate the need to use an innovative solution in measurements of building structures using RTN GNSS technology. It provides high accuracy and reliability of the obtained measurement results.

\section{Research Methods and Research Experiment}

For a detailed review of the algorithm developed by the author, called the method of vector translation, a research experiment was conducted on the object located in Węgierska Górka in the Silesian Province (Fig. 1). A research sample of the object included the corners of single-family houses and service buildings. In order to determine the base points (A, B, C, etc.), RTN GNSS technology was applied, using the network of TPI reference stations and the receiver HiperPro by Topcon. Basing on the base points and using the classical method of line-line intersection, $X$ and $Y$ coordinates of the corners of building structures were calculated in the PL-2000 system. Then, using the algorithm of vector translation, the new and final positions of the corners were determined. The obtained values of the final coordinates were referred to the coordinates of the same points determined by the tacheometric method, tied to the measurement control. The reasons for such a reference and the uniformity of the compared results have been presented in [2,3].

For the editorial purposes of this article, additional auxiliary designations of the individual types of measurements were introduced:

- tacheometric method - T,

- the method of line-line intersection - PP,

- the method of line-line intersection, taking into account the method of vector addition $-P P_{v a^{\prime}}$

- the method of line-line intersection, taking into account the method of vector translation $-P P_{t v^{\prime}}$

- open frame tape measurement $-R$.

Assessment of the reliability of the obtained results began with a comparison of the coordinates of the methods $T-P P_{t v^{\prime}}$ the calculation of the differences $\mathrm{d} X, \mathrm{~d} Y$ and the length of the vector $\mathrm{d} L$ (Tab. 1).

Graphical representation of the development of the results contained in Table 1 has been illustrated in Figure 2.

When analyzing the graph (Fig. 2), we can observe the dominant interval of $\pm 0.05 \mathrm{~m}$ with coordinate differences. This interval accounts for $100 \%$ of the values from the entire research sample for the parameter $d X, 89 \%$ for $d Y$ and $86 \%$ for the length of the vector $d L$. When we refer these proportions to the specific values in Table 1, we can notice that for the parameter $\mathrm{d} Y$ only four values exceed the said interval of $\pm 0.05 \mathrm{~m}$ (the corners: $23,24,25,28$ ). 

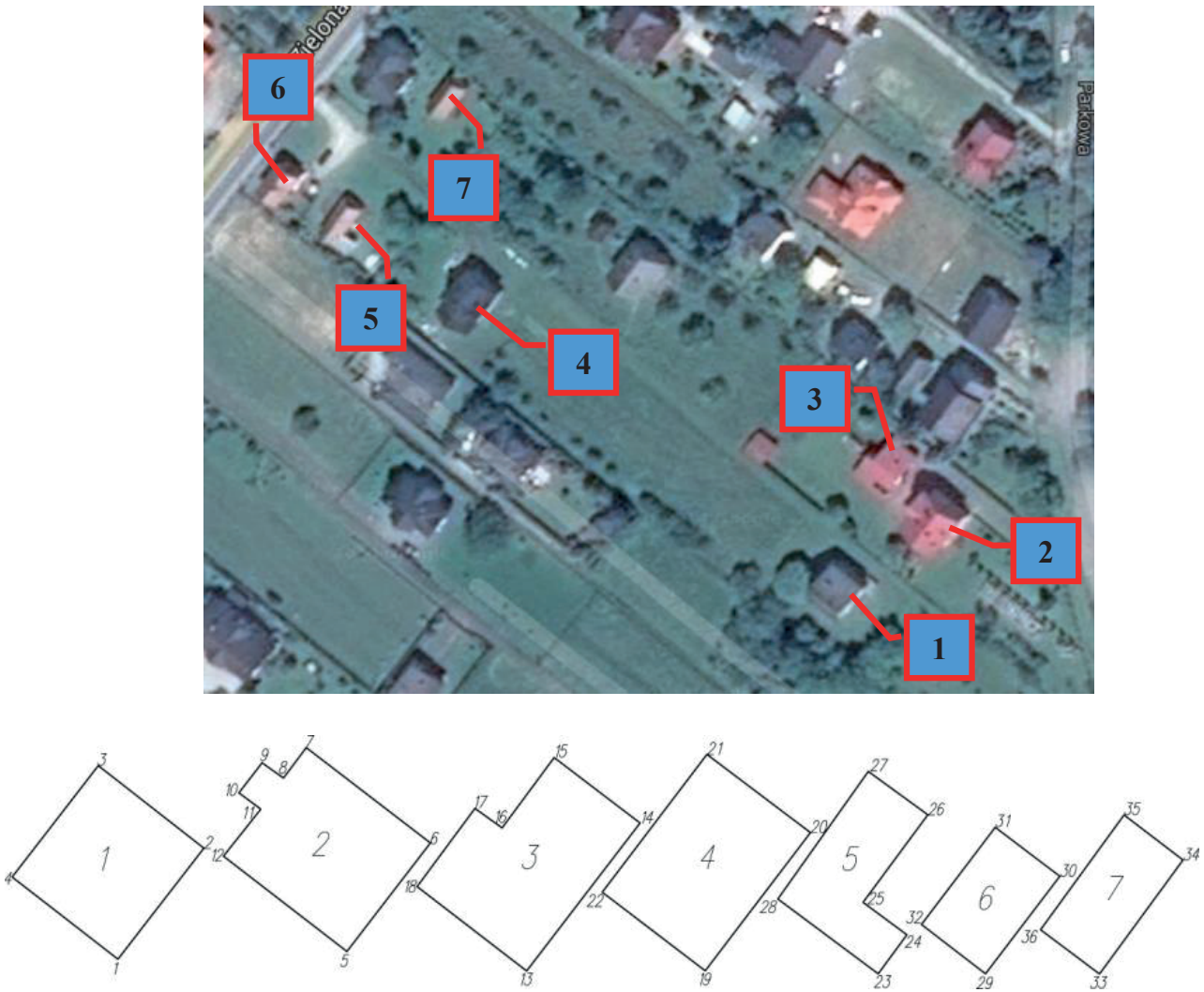

Fig. 1. Location of the buildings on the test object in Węgierska Górka Source: [5]

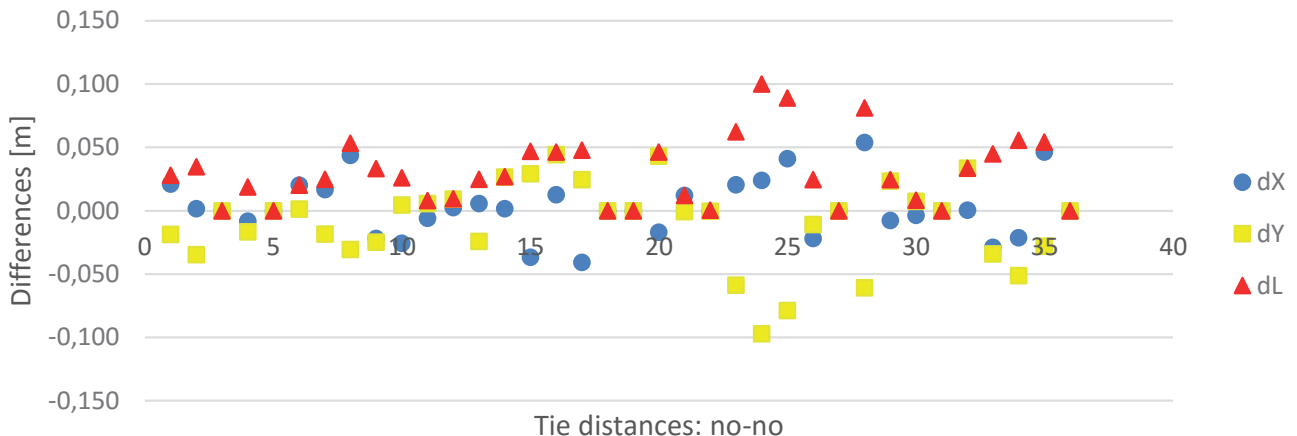

Fig. 2. Development of differences in the values of the coordinates $d X, d Y$ and length of the vector $\mathrm{d} L$ in the relationship of the methods: tacheometric and line-line intersection, taking into account the method of vector translation 


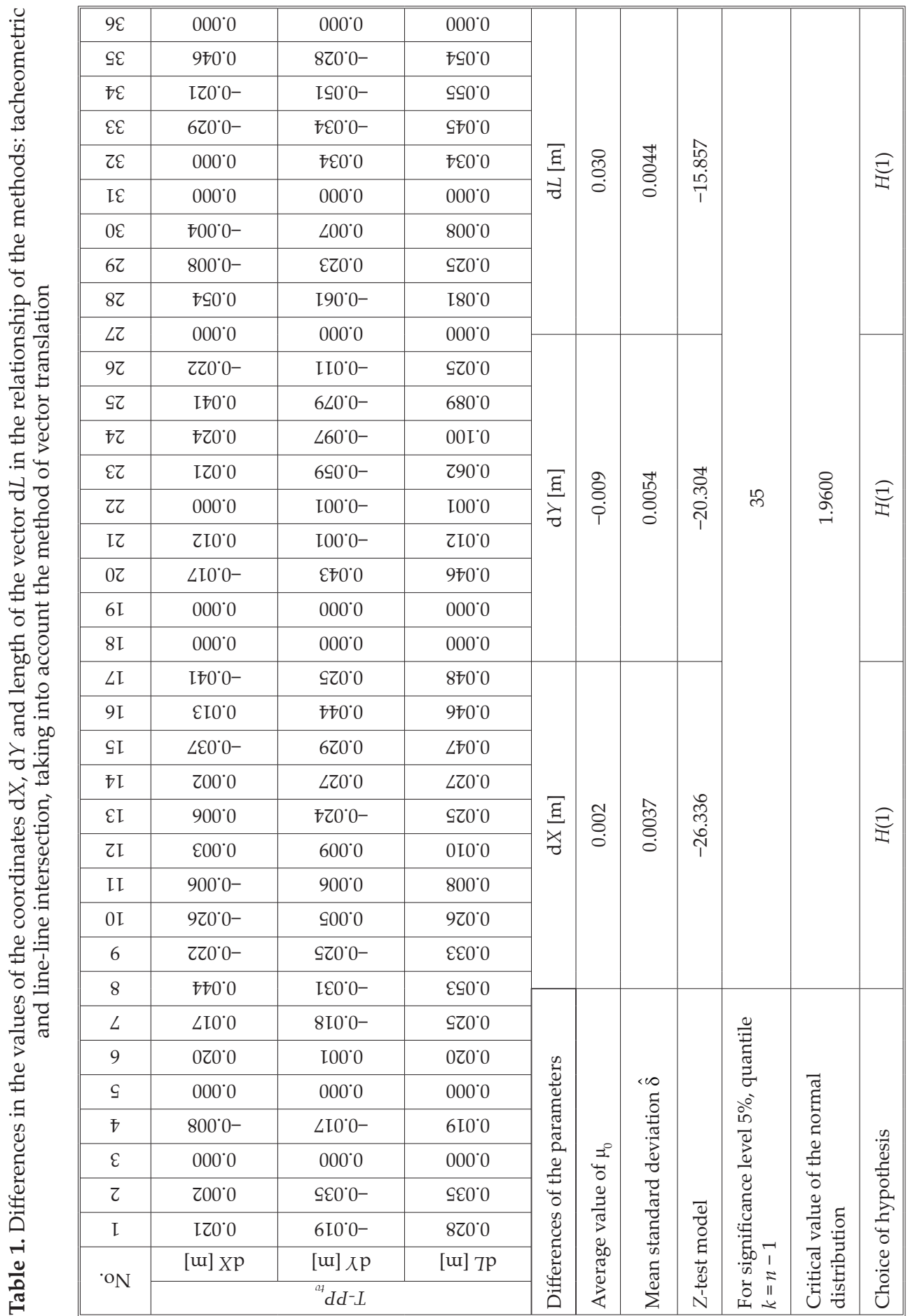


These are the points located in the western part of the service building with the horizon obscured by the trees. On the other hand, for the length of the vector $\mathrm{d} L$ (Tab. 1), five points have the interval of coordinate differences greater than $\pm 0.05 \mathrm{~m}$. These are the same points as in the case of $\mathrm{d} Y$ values, and additionally the corner 34, which is also located in measurement conditions which are difficult for the RTN GNSS mode.

It should also be emphasized that the measurements were carried in summer when the tree leaves are a significant obstacle to their performance. It should also be noted that none of the coordinate differences exceeded the mean error of the position of field details of the first-order accuracy, i.e. $\pm 0.10 \mathrm{~m}$, compared to the same points determined by tacheometric method.

The reliability assessment of the obtained coordinate differences was further brought to the statistical analysis. Thus, for the research sample, null hypothesis $H_{0}$ was defined, which is as follows: the mean value of $\mu$, for the differences in the values of the coordinates $d X, d Y$ and for the length of the vector $d L$ in the relationship of the methods $T-P P_{t y^{\prime}}$ is equal to the predetermined value of $\mu_{0}=0.10 \mathrm{~m}$ (formula (1)):

$$
H_{0}: \mu=\mu_{0}
$$

Then, alternative hypothesis $H_{1}$ was formulated: the mean value of $\mu$, for the differences in the values of the coordinates $d X, d Y$ and for the length of the vector $d L$ in the relationship of the methods $T-P P_{t y}$ is less than the predetermined value of (formula (2)):

$$
H_{1}: \mu \leq \mu_{0}
$$

The interpretation of the predetermined value at $\mu_{0}=0.10 \mathrm{~m}$ has been presented in [1]. The results of the statistical analysis have been contained in Table 1. For each analyzed parameter $(\mathrm{d} X, \mathrm{~d} Y, \mathrm{~d} L)$, the mean value of, the mean standard deviation (formula (3)), and the third model of the $Z$ test of the single mean value (formula (4)) were calculated at the significance level $\alpha=5 \%$ and the $k=n-1$ degrees of freedom:

$$
\delta(\mu)=\frac{\hat{\delta}}{\sqrt{n}}
$$

where:

$\delta$ - standard deviation for the differences in the values of the coordinates $\mathrm{d} X, \mathrm{~d} Y$ and the length of the vector $\mathrm{d} L$ in the relationship of the methods T-PP ${ }_{t v^{\prime}}$

$n$ - number of differences in the values of the coordinates $\mathrm{d} X, \mathrm{~d} Y$ and the length of the vector $\mathrm{d} L$ in the relationship of the methods $T-P P_{t v}$ :

$$
Z=\frac{\mu-\mu_{0}}{\delta(\mu)}
$$


Verification of the formulated hypotheses (Tab. 1) is unambiguous for each of the studied parameters $\mathrm{d} X, \mathrm{~d} Y, \mathrm{~d}$ L: the mean value of $\mu$, for the differences in the values of the coordinates $d X, d Y$ and for the length of the vector $d L$ in the relationship of the methods $T-P P_{t o}$ is statistically significant, resulting in the rejection of the hypothesis $H_{0}$ in favor of the hypothesis $H_{1}$.

If we compare the results yielded from a model of the $Z$ test of the single mean value against the critical value of the normal distribution (very large differences), and additionally, we analyze small mean values of the coordinate differences, we can conclude that the results of the verification of the hypotheses (Tab. 1) and the development of the values $\mathrm{dX}, \mathrm{d} Y$ and $\mathrm{d} L$ (Fig. 2) prove a significant advantage of applying the method of vector translation in modeling the coordinates of the determined points. The use of the algorithm developed by the author significantly increases the reliability of the position of corners of building structures measured in the RTN GNSS mode.

In order to emphasize the importance of this innovative method in the implementation of the measurements of building structures even more, frequency histograms for the parameters $\mathrm{d} X, \mathrm{~d} Y$ and $\mathrm{d} L$ were drawn (Figs 3-5).

As it was already mentioned before, only four points for the parameter $\mathrm{d} Y$ and five points for $\mathrm{d} L$ exceed the value of $\pm 0.05 \mathrm{~m}$. Looking at the histograms below, we can additionally notice that most of the differences in the values of the coordinates $d X$ (Fig. 3), $d Y$ (Fig. 4) and the length of the vector $d L$ (Fig. 5) fluctuates within $\pm 0.02 \mathrm{~m}$, which makes them completely negligible. They represent $58 \%, 50 \%$ and $36 \%$ of the whole research sample, respectively.

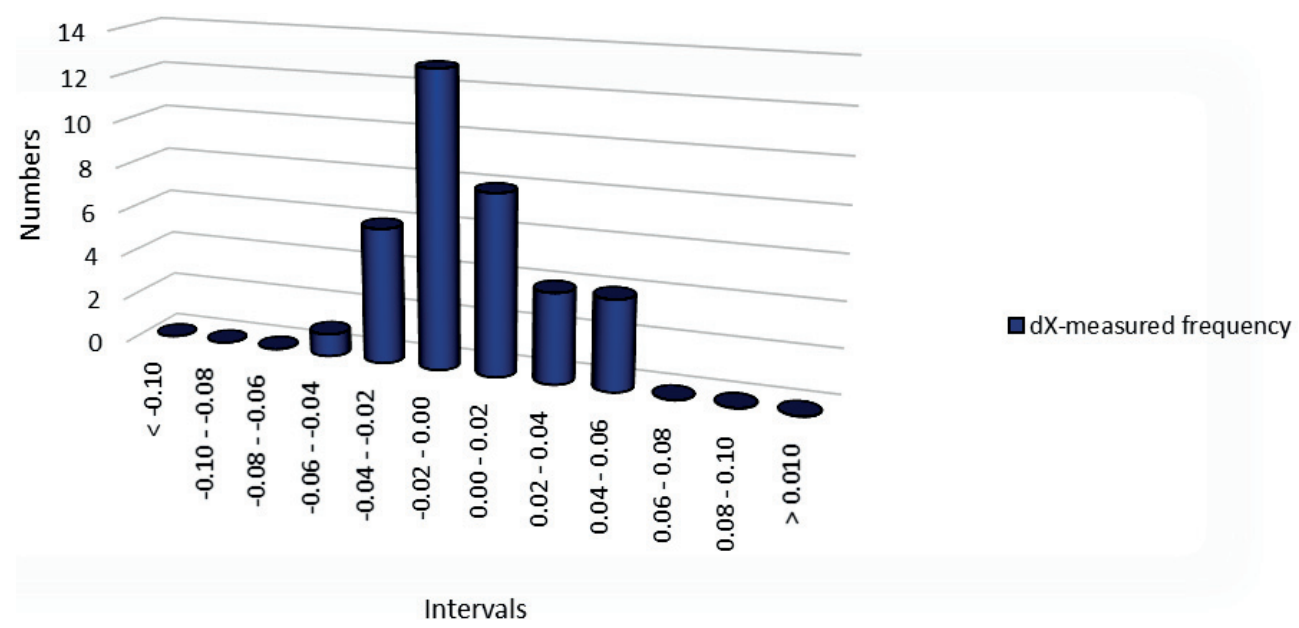

Fig. 3. Frequency histogram for the differences in the values of the coordinates $d X$ on the corners of the building in the relationship of the methods: tacheometric and line-line intersection, taking into account the method of vector translation 


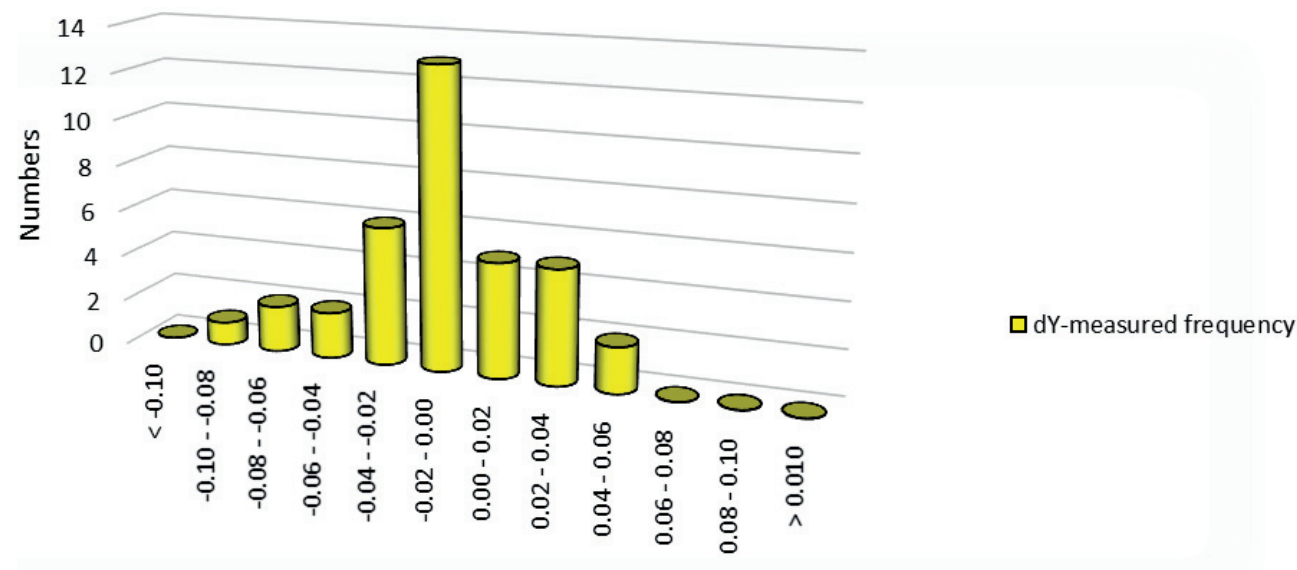

Intervals

Fig. 4. Frequency histogram for the differences in the values of the coordinates $\mathrm{d} Y$ on the corners of the building in the relationship of the methods: tacheometric and line-line intersection, taking into account the method of vector translation

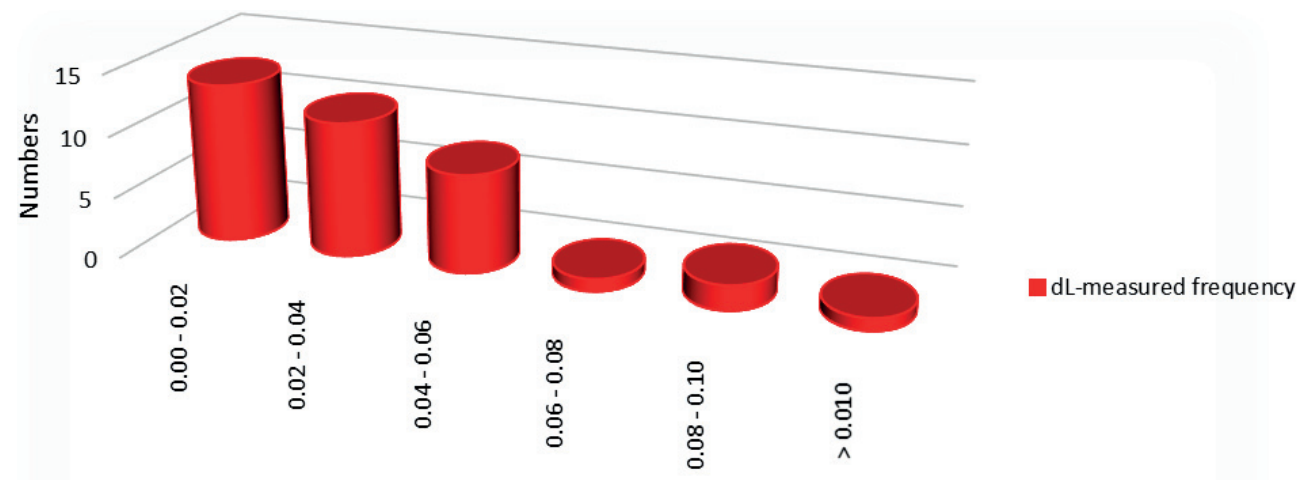

Intervals

Fig. 5. Frequency histogram for the differences in the length of the vector $d L$ on the corners of the building in the relationship of the methods: tacheometric and line-line intersection, taking into account the method of vector translation

When we double the intervals of the obtained coordinate differences to $\pm 0.04 \mathrm{~m}$, then automatically the frequency of the occurrence of the examined differences will rise to $86 \%$ for $d X, 81 \%$ for $d Y$ and $67 \%$ for $d L$. Thus, it is noticeable, that still at low values of the coordinate differences, their incidence is increasing significantly. It should also be emphasized that for the parameter $\mathrm{d} X$ none of the obtained values exceeds $\pm 0.06 \mathrm{~m}$ and for $\mathrm{d} Y$ only three points fall within the range of $\pm 0.06 \mathrm{~m}$ to $\pm 0.10 \mathrm{~m}$. 
The advantages of using the method of vector translation to modify the coordinates of corners of building structures determined in the RTN GNSS mode are also illustrated in Figure 6. This Figure depicts the mean differences in the values of the coordinates $\mathrm{d} X, \mathrm{~d} Y$ and $\mathrm{d} L$ of the points being determined, which were obtained from the measurements before and after applying the method of vector translation. The "before" version concerned the determination of corners of buildings in real time, based on the measurement of the base points using the classical method of line-line intersection. The "after" version additionally took into account the method of vector translation. In Figure 6, attention is turned to a very large decrease in the mean values of $d X$ and $d L$ between the compared methods, more than seven times for $\mathrm{d} X$ and almost 4 times for the vector $\mathrm{d} L$, respectively. Only $\mathrm{d} Y$ remains at the same level, but with the opposite sign.

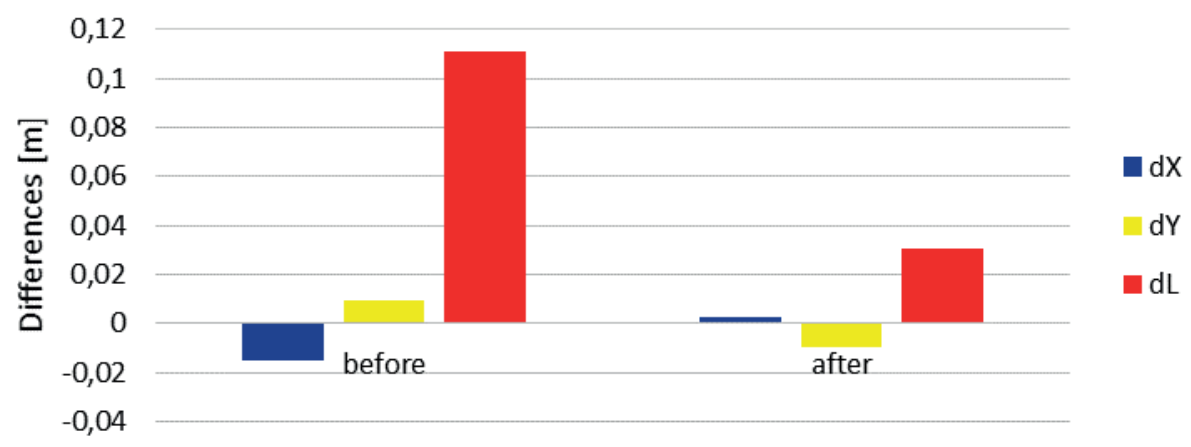

Fig. 6. Mean values of the differences in the coordinates $\mathrm{d} X, \mathrm{~d} Y$ and the length of the vector $\mathrm{d} L$ before and after applying the method of vector translation

On the basis of the compared mean coordinate differences from Figure 6, the range of the development of these parameters should be considered (Figs 7, 8). The minimum (Fig. 7) and maximum (Fig. 8) values support the applicability of the method of vector translation in shaping the coordinates of the corners of building structures. As it is in the case of the values of the mean coordinate differences, also in these ranges the tendency to minimize the extremes is constant. After applying the method of vector translation, for the minimum values, the coordinate differences decreased by more than 3/4 for the parameter $d X$ and by $2 / 3$ for $d Y$. Only the length of the vector $\mathrm{d} L$ did not change, which is absolutely right in this case, because it is at the zero level in both measurement versions. Similar results are obtained in the case of the maximum values of the obtained coordinate differences (Fig. 8). The extremes of $\mathrm{d} X$ and $\mathrm{d} L$ decrease by $80 \%$, and $\mathrm{d} Y$ by close to $90 \%$.

The last step in assessing the reliability of the coordinates of the determined corners of buildings using the algorithm of vector translation was comparing the geometric design of the building with its actual state, i.e. the mutual relationships of the so-called tie distances as control measures. 


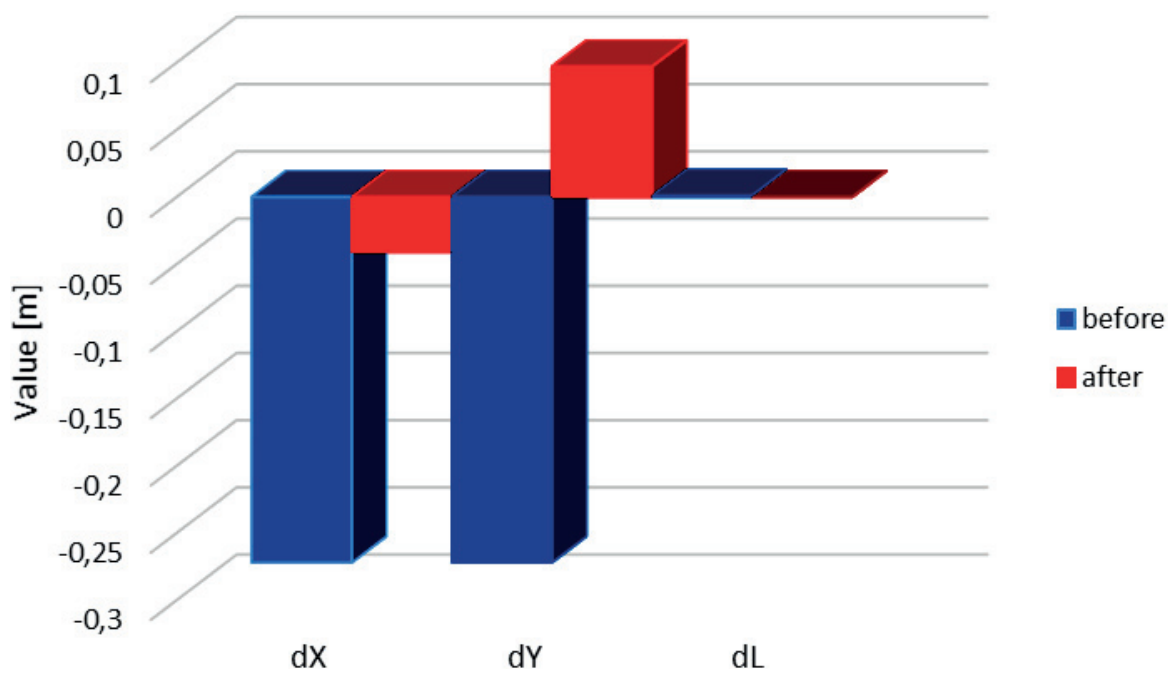

Fig. 7. Minimum values of the differences in the coordinates $d X, d Y$ and the length of the vector $\mathrm{d} L$ before and after applying the method of vector translation

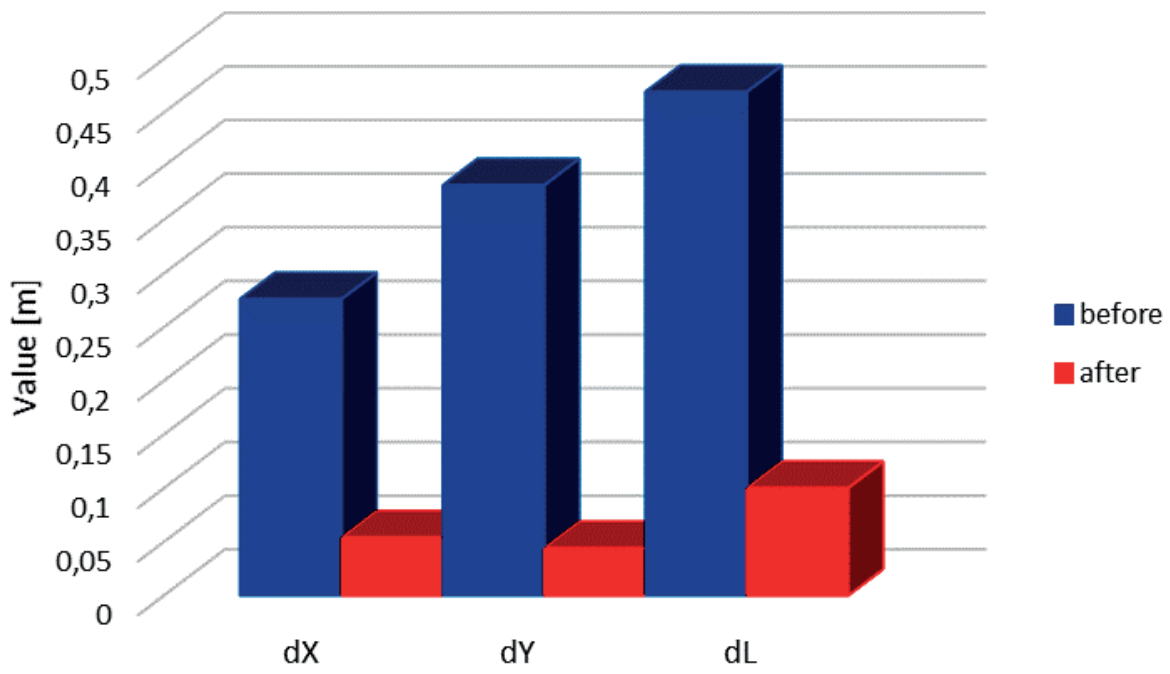

Fig. 8. Maximum values of the differences in the coordinates $d X, d Y$ and the length of the vector $\mathrm{d} L$ before and after applying the method of vector translation

The results of this comparison are very well presented in Table 2, which summarizes the three measurement methods: classical $T$ tacheometry, line-line intersection taking into account the method of vector addition $P P_{v a^{\prime}}$ described in detail in [2], and the currently analyzed method of line-line intersection taking into account the algorithm of vector translation $P p_{t v^{\circ}}$. 


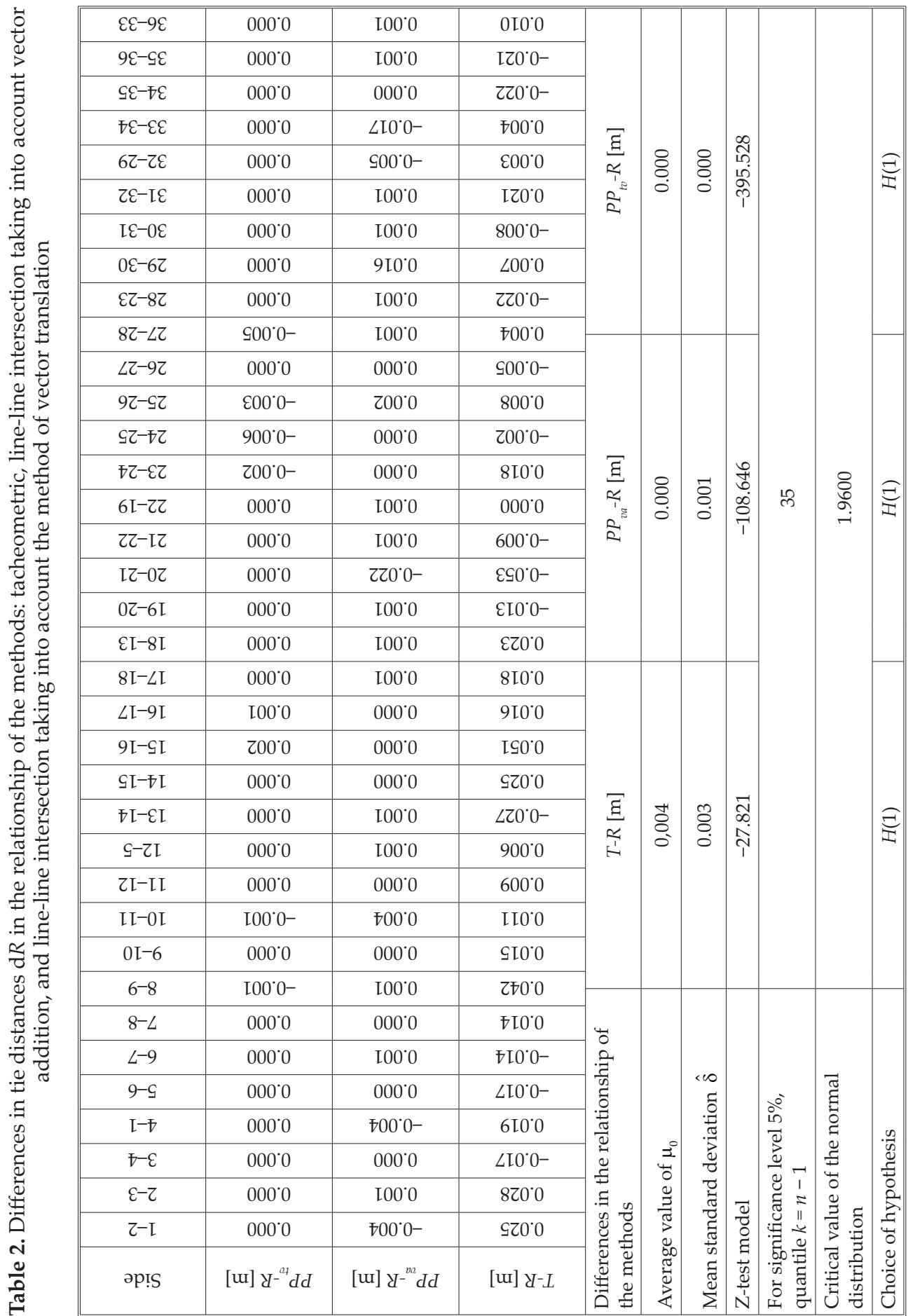


Table 2 presents the statistical analysis of the obtained differences in tie distances between individual methods. Regarding the relationships of the methods $T-R, P P_{v a}-R$ and $P p_{t v}-R$, null hypothesis $H_{0}$ and the alternative hypothesis $H_{1}$ were formulated, which were defined in the same way as in the case of coordinate differences contained in Table 1. The statistical analysis also used the same formulas (1)-(4). Conclusions from the conducted analysis are favorable for the assessment of the algorithm of vector translation. First of all, verification of the hypotheses states that the mean value of $\mu$, for the differences in tie distances $d R$ in the relationships of the methods $T-R, P P_{v a}-R$ and $P P_{t v}-R$ is statistically significant, resulting in the rejection of the hypothesis $H_{0}$ in favor of the hypothesis $H_{1}$. Another positively evaluated argument for the $P P_{t o}$ method (for the other methods as well) is the mean value of $\mu$ from the obtained differences $\mathrm{d} R$, which is at the zero level. However, when we take a look at the intervals of the mean value of $\mu$, we will notice that by far the best results are achieved by the method of vector translation, where the extremes are at the level of single millimeters. In the case of the method of vector addition, these values fluctuate within $\pm 0.02 \mathrm{~m}$, and in tacheometry they fall within $\pm 0.05 \mathrm{~m}$. Although tacheometry theoretically yields the weakest results, all measurement methods can certainly be considered to be sufficiently accurate to measure these field details which are difficult to access, such as corners of building structures.

\section{Summary and Conclusions}

In this article, the author has attempted to prove that, with some improvements in the calculation mechanisms of classical method of line-line intersection used in the RTN GNSS surveying, it is possible to determine a reliable position of corners of building structures. In the conducted research experiment, the author compared the results of the measurements of the corners of building structures, obtained from RTN GNSS surveying and tacheometry, using the method of vector translation. As the comparisons and the conducted statistical analysis show, the algorithm developed by the author is at the same level of accuracy and reliability of the determined coordinates of the corners of building structures as the classical surveying method - tacheometry. Some research aspects, such as comparison of tie distances, for example, suggest even greater accuracy of this innovative solution than of tacheometry. This does not mean, however, that the new solution can replace the existing measurement technique completely. As it is the case in every measurement technology, also in the method of vector translation, there are situations in which the obtained results differ significantly from the values assumed to be the most probable. Their incidence, however, is at a very negligible level, and their values do not exceed the maximum error of the position of field details of the first-order accuracy, i.e. $\pm 0.10 \mathrm{~m}$. The empirical evidence, which has been presented in the tabular analyses and Figures, strongly supports the need to use this innovative algorithm in RTN 
GNSS surveying to determine the positions of building structures. When carrying out measurements using the method of vector translation, adequate accuracy of the measurement results and reliability of the obtained coordinates of the corners of an object are also ensured.

\section{References}

[1] Krzyżek R.: Reliability analysis of the results of RTN GNSS surveys of building structures using indirect methods of measurement. Geodesy and Cartography, vol. 63, no. 2, 2014, pp. 161-181.

[2] Krzyżek R.: Routing corners of building structures - by the method of vector addition - measured with RTN GNSS surveying technology. Geodesy and Cartography, submitted for review in April 2015.

[3] Krzyżek R.: Modernization of the method of line-line intersection using RTN GNSS technology for determining the position of corners of buildings. Artyficial Satellites Journal of Planetary Geodesy, vol. 50, no. 1, 2015, pp. 41-57.

[4] Rozporzadzenie Ministra Spraw Wewnętrznych i Administracji z dnia 9 listopada 2011 r. w sprawie standardów technicznych wykonywania geodezyjnych pomiarów sytuacyjnych i wysokościowych oraz opracowywania i przekazywania wyników tych pomiarów do państwowego zasobu geodezyjnego i kartograficznego. Dz.U. 2011, nr 263, poz. 1572 [Regulation of Minister of Interior and Administration - in case of technical standards of performing detailed surveys and working out and sending results of these surveys to National Geodetic and Cartographic Database. Journal of Laws 2011, no. 263, item 1572].

[5] mapy.geoportal.gov.pl/imap, state for 2014. 